\title{
Prevalence of Sleep Disorders in Adolescents and its Relation with Screen Time during the COVID-19 Pandemic Era
}

\author{
I. Gusti Ayu Trisna Windiani* ${ }^{\star}$ Ni Made Reditya Noviyani, I. Gusti Agung Ngurah Sugitha Adnyana, \\ Ni Luh Sukma Pratiwi Murti, Soetjiningsih Soetjiningsih \\ Department of Child Health, School of Medicine, Universitas Udayana, Sanglah Hospital, Denpasar, Bali, Indonesia
}

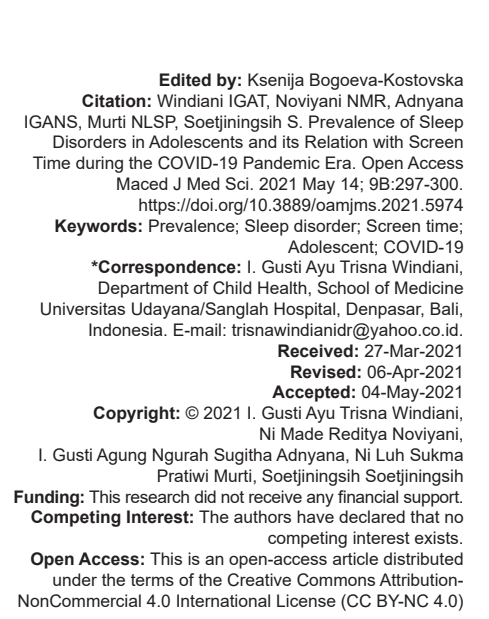

Abstract

BACKGROUND: Sleep disorders encompass disturbances in the amount, quality, or timing of sleep. Several factors have contributed to sleep disorders in adolescents, including the use of electronic devices. In the COVID-19 pandemic era, there is a rising trend of screen time.

AIM: The objective of the study was to identify the prevalence of sleep disorders in adolescents and its relation with screen time during the COVID-19 pandemic era.

METHODS: This is a cross-sectional study involving students aged 15-18 years at three State High School, Denpasar, and Santo Yoseph Senior High School, Denpasar, in August 2020, using purposive sampling method. Data collections on characteristics of the subjects and Pittsburgh Sleep Quality Index (PSQI) were performed using Google Forms. Statistical analysis was performed using Chi-square test.

RESULTS: A total of 243 students participated in this study, of which 39 students were excluded due to chronic diseases and consumption of caffeine within $6 \mathrm{~h}$ before bedtime. Sleep disorder was found in $30.4 \%$ of subjects and mostly characterized by sleep duration of $<8 \mathrm{~h}(62.9 \%)$. Analysis of the association between screen time and sleep disorders showed a significant result $(P R=3.8,95 \% \mathrm{Cl}=1.09-13.1, \mathrm{p}=0.02)$.

CONCLUSION: The prevalence of sleep disorders in adolescents is considerably high. There is an association between screen time and sleep disorders that occur in adolescents during the COVID-19 pandemic era.

\section{Introduction}

Sleep is a complex neurological process that plays a major role in many vital physiologic functions, including energy conservation, brain waste clearance, and brain development. Normal sleep is divided into non-rapid eye movement (NREM) and rapid eye movement (REM), with changes between NREM and REM occurring 4-5 times during sleep [1]. Prior study has shown that the duration of sleep is decreased as people age. The American Academy of Sleep Medicine (AASM) recommends that adolescents aged 13-18 years should have $8-10 \mathrm{~h}$ of sleep per day to get optimal health [2]. Several epidemiological studies have demonstrated that adolescents can have less amount of sleep duration. The National Sleep Foundation found $75 \%$ reduction in sleep duration ( $<8 \mathrm{~h}$ a day) in the $12^{\text {th }}$ grade students [3], [4], [5].

Sleep disorders comprise disturbances in the amount, quality, or timing of sleep. Sleep disorders can have short-term and long-term impacts. The short-term impacts of sleep disorder are decrease in concentration, attention, quality of life, and productivity as well as an increase in work and traffic accidents. The long-term impacts of sleep disorder are increased morbidity and mortality associated with high blood pressure, obesity, type 2 diabetes mellitus, coronary artery disease, heart failure, stroke, and memory problems [6].

Several factors have contributed to sleep disorders in adolescents, such as the use of electronic devices, caffeine consumption, chronic illness, mood and anxiety disorders, as well as behavioral disorders (e.g., attention deficit-hyperactivity disorder) [7], [8]. Children aged 8-18 years in America can spend approximately $7 \mathrm{~h} /$ day of screen time [9]. According to the Indonesian Pediatrics Society, the recommendation of screen time for children older than 2 years is not more than $2 \mathrm{~h}$ /day [10]. A study by Kenney et al. showed that $80 \%$ of adolescents with screen time of $5 \mathrm{~h}$ or more had less sleep duration [11]. Exposure to light from any screen media using light-emitting diodes (LEDs) for $5 \mathrm{~h}$ at night can also reduce the subjective sleep quality [12]. In pre-pandemic era, the screen media usage has an effect of $13 \%$ on sleep quality [13].

During coronavirus disease (COVID)-19 pandemic, children of all ages spend approximately $6 \mathrm{~h} /$ day on digital devices as compared to $3 \mathrm{~h}$ in 
pre-pandemic era, suggesting a 2-fold increase in screen time [3], [14]. A study by Eyimaya et al. showed that screen time has increased in $71.7 \%$ of children during the COVID-19 pandemic [15]. Thus, this study aims to investigate the prevalence of sleep disorders in adolescents in senior high schools in Denpasar and its relation with screen time during the COVID-19 pandemic era.

\section{Methods}

This is an analytical study with a crosssectional design, conducted in August 2020, involving students aged 15-18 years at three State High School, Denpasar, and Santo Yoseph Senior High School, Denpasar. A total of 243 students participated in this study and these subjects were obtained using purposive sampling method. The exclusion criteria include children who had chronic diseases (allergic rhinitis, asthma, systemic lupus erythematosus, and heart disease) and caffeine consumption $6 \mathrm{~h}$ before bedtime over the previous month. Data regarding characteristics of the subjects and sleep quality assessment, as measured by Pittsburgh Sleep Quality Index (PSQI), were collected using Google Forms. The data were then analyzed statistically using Chisquare test.

In this study, screen time is defined as the amount of time spent using a device with a screen such as cell phone, tablet, computer, television, and PlayStation. Screen time is classified as positive if the duration is more than or equal to $5 \mathrm{~h} / \mathrm{school}$ day. This cutoff is determined based on a study by Kenney et al. which showed that adolescents had less sleep duration, if they have screen time of $5 \mathrm{~h}$ or more per day [11]. The online learning is not taken into account as screen time in this study.

Sleep disorders are characterized by disruption in the amount, quality or timing of sleep. In this study, the sleep quality assessment was performed using PSQI instrument (Indonesian version) with sensitivity and specificity of $89.6 \%$ and $86.5 \%$ (Cronbach's $\alpha$ score 0.72 ). The PSQI contains 19 self-rated questions grouped into seven components (subjective sleep quality, sleep latency, sleep duration, habitual sleep efficiency, step disturbances, use of sleep medication, and daytime dysfunction), each of which has a range of 0-3 points. The seven component scores are then added to yield one global score, with a range of 0-21 points. A PSQI global score of more than 5 indicates the presence of sleep disorder [16], [17]. This study was approved by the Research Ethics Committee of School of Medicine, Universitas Udayana/Sanglah Hospital (2030/UN14.2.2.VII.14/ LT/2020).

\section{Results}

A total of 243 students from three State High School, Denpasar, and Santo Yoseph Senior High School, Denpasar, participated in the study. Thirty-nine students who had chronic diseases (allergic rhinitis, asthma, systemic lupus erythematosus, and heart disease) and caffeine consumption $6 \mathrm{~h}$ before bedtime over the previous month were excluded, as described in Figure 1.

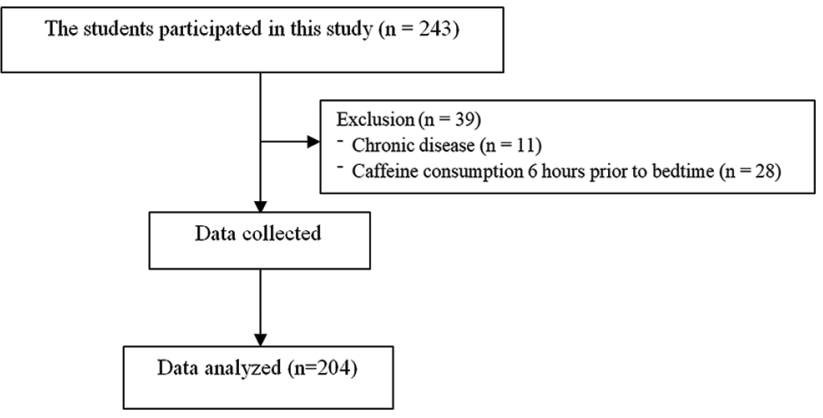

Figure 1: Study flowchart

The characteristics of subjects are described in Table 1. The use of screen media was higher in male subjects $(51.5 \%)$ compared to female subjects. Based on the assessment using PSQI instrument, we found that $30.4 \%$ of subjects experienced sleep disorders, with a PSQI score of more than 5. The component of sleep disorders that most commonly found in this study was the sleep duration of $<8 \mathrm{~h}(62.9 \%)$. The distribution of subjects based on the assessment of PSQI instrument is shown in Table 2.

Table 1: Characteristics of study subjects

\begin{tabular}{ll}
\hline Characteristics & $\mathrm{n}=204$ \\
\hline Age, median (range), years & $16(15-18)$ \\
Gender, $\mathrm{n}(\%)$ & $105(51.5)$ \\
$\quad$ Male & $99(48.5)$ \\
$\quad$ Female & $204(100)$ \\
Screen media usage, $\mathrm{n}(\%)$ & \\
The presence of television in the bedroom, $\mathrm{n}(\%)$ & $95(46.6)$ \\
$\quad$ Yes & $109(53.4)$ \\
$\quad$ No & $178(87.3)$ \\
Screen time, $\mathrm{n}(\%)$, hours & $26(12.7)$ \\
$\quad \geq 5$ & \\
$\quad<5$ & $62(30.4)$ \\
Sleep disorder, $\mathrm{n}(\%)$ & $142(69.6)$ \\
$\quad$ Yes & \\
$\quad$ No &
\end{tabular}

This result showed that one adolescent had more than 1 sleep disorders. No adolescent exhibited disorder in habitual sleep efficiency and consumption of sleep medications as assessed by PSQI. Bivariate analysis showed that screen time has an association with sleep disorder occurring in adolescents (PR 3.8, 95\% Cl 1.09-13.1, $p=0.02$ ) (Table 3).

Table 2: Distribution of subjects with sleep disorder based on the assessment of PSQI instrument $(n=62)$

\begin{tabular}{ll}
\hline Components of PSQI & $\mathrm{n}(\%)$ \\
\hline Bad subjective sleep quality & $31(50)$ \\
Sleep latency $>30 \mathrm{~min}$ & $36(58)$ \\
Sleep duration $<8 \mathrm{~h}$ & $39(62.9)$ \\
Step disturbances & $22(35.4)$ \\
Daytime dysfunction & $31(50)$ \\
\hline
\end{tabular}




\section{Discussion}

Sleep disorder encompasses disturbances in the amount, quality, or timing of sleep. This study showed that the prevalence of sleep disorder in adolescents aged 15-18 years in three State High School and Santo Yoseph Senior High School, Denpasar, was $30.4 \%$, as measured using PSQI. Study by Ohida et al. manifested that the prevalence of sleep disorders varied from $15.3 \%$ to $39.2 \%$, depending on the type of sleep disorder [18]. The most common component of sleep disorder in this study is the sleep duration of $<8 \mathrm{~h}(62.9 \%)$ followed by sleep latency of more than 30 min (58\%). According to the National Sleep Foundation, sleep duration of $<8 \mathrm{~h}$ in adolescents is classified as insufficient [5]. One of the common causes of sleep disorder that occurs in adolescents is the excessive use of technology, such as television, computer, and cell phone [7].

Table 3: Analysis of the association of screen time to sleep disorder

\begin{tabular}{llllll}
\hline Variables & \multicolumn{2}{l}{ Sleep disorder } & PR & $95 \% \mathrm{Cl}$ & p value \\
\cline { 2 - 3 } & Yes $(\mathrm{n}=62)$ & No $(\mathrm{n}=142)$ & & & \\
\hline Screen time, $\mathrm{n}(\%)$ & & & & & \\
$\quad$ Positive & $59(33.1)$ & $119(66.9)$ & & & \\
$\quad$ Negative & $3(11.5)$ & $23(88.5)$ & & & \\
\hline
\end{tabular}

In the COVID-19 pandemic era, there are social distancing and stay-at-home regulations as safety measures to prevent transmission of SARSCOV 2. As a result, people spend more time at home and this may contribute to a 2-fold increase in screen media usage. Children of all ages can spend nearly 6 $\mathrm{h} /$ day of screen time [13]. In this study, we found that $87.3 \%$ of subjects had screen time of at least $5 \mathrm{~h}$. The analysis of association between screen time and sleep disorder showed a statistically significant result (PR 3.8, 95\% Cl 1.09-13.1, $p=0.02$ ). This result is consistent with more than $90 \%$ of observational studies with cross-sectional design or prospective approach that assessed the association between screen time (television, computer, video game, and cell phone) and various sleep parameters, suggesting that longer screen time was associated with delay of sleep latency and reduction in sleep duration among children and adolescents [19]. This study also showed that $46.6 \%$ of adolescents had a television in the bedroom. Several studies have found that the presence of television in the bedroom is associated with sleep disorder. A study by Shochat et al. also demonstrated that adolescents who had television in their bedroom experienced longer sleep latency and shorter sleep duration [20].

There are several possible mechanisms behind the association between screen time and sleep disorders. Screen time can directly affect sleep by altering the sleep time and duration, especially if the electronic device is located in the bedroom. The use of digital device before bedtime can increase emotional arousal, causing increase in sleep latency and reducing total sleep time. The bright light from the screen can disrupt sleep through suppression and delay of the circadian rhythm of melatonin, a sleep stimulating hormone, which will normally increase at night before bedtime. Sleep can also be negatively affected by electromagnetic radiation from the screen. Another mechanism that can contribute to sleep disorder is physical discomfort, for instance muscle pain and headache due to prolonged use of digital devices [7], [21].

The circadian system has a number of vital roles in sleep/wake regulation, associated with darkness and increased melatonin level. Melatonin acts as a signal to start the biological clock at night. Exposure to light at night can suppress the secretion of melatonin. The circadian photoreceptor system has a peak sensitivity to blue light with a wavelength of $450-480 \mathrm{~nm}$, leading to suppression of melatonin secretion [22], [23]. Most electronic devices, such as computer, television, cell phone, and tablet, use light-emitting diodes (LEDs); which have blue color spectrum with a peak wavelength of $460 \mathrm{~nm}$. Exposure to light from digital screen that uses LEDs compared to non-LEDs for $5 \mathrm{~h}$ at night can reduce melatonin secretion. Delayed melatonin secretion due to exposure to light from the digital screen can cause a delay in sleep initiation, thereby contributing to sleep disorder. Exposure to light for several hours before bedtime can also prolong sleep latency and decrease the rapid eye movement (REM) phase of sleep [12], [24].

One of the limitations from this study includes the determination of sleep disorder using a screening tool by PSQI instrument. The diagnosis of sleep disorder should be confirmed by polysomnography (PSG). Furthermore, there were some variables that were not measured in this study, including the time of digital screen usage before bedtime, the presence of electronic devices in the bedroom other than television, comparison of the screen time on weekdays and weekends, use of LED - emitting devices, sleep hygiene, and other confounding factors that can affect sleep disorders, including mood disorders, anxiety, and attention deficit-hyperactivity disorder. Consequently, further studies are needed to determine the effect of screen time on sleep disorder in adolescents.

\section{Conclusion}

This study concludes that the prevalence of sleep disorder in adolescents is substantially high. Screen time has a statistically significant association with sleep disorder that occurs in adolescents in the COVID-19 pandemic era. We suggest that the screen time in adolescent does not exceed 2 h/day, in line with the recommendation from Indonesian Pediatrics Society. 


\section{References}

1. Kumar VM. Sleep and sleep disorders. Indian J Chest Dis Allied Sci. 2008;50(1):129-35. PMid:18610697

2. Paruthi S, Brooks LJ, D'Ambrosio C, Hall WA, Kotagal S, Lloyd RM, et al. Recommended amount of sleep for pediatric populations: A consensus statement of the American academy of sleep medicine. J Clin Sleep Med. 2016;12(6):785-6. https:// doi.org/10.5664/jcsm.5866

PMid:27250809

3. Lund HG, Reider BD, Whiting AB, Prichard JR. Sleep patterns and predictors of disturbed sleep in a large population of college students. J Adolesc Health. 2010;46(2):124-32. https://doi. org/10.1016/j.jadohealth.2009.06.016

PMid:20113918

4. Urner M, Tornic J, Bloch KE. Sleep patterns in high school and university students: A longitudinal study. Chronobiol Int. 2009;26(6):1222-34. https://doi. org/10.1080/07420520903244600

PMid:19731114

5. National Sleep Foundation. 2006 Teens and Sleep. Washington, DC: National Sleep Foundation; 2006. Available from: https:// www.sleepfoundation.org. [Last accessed on 2020 May 18].

6. Chokroverty S. Overview of sleep and sleep disorders. Indian J Med Res. 2010;131:126-40. https://doi.org/10.1542/ peds.2014-1696

PMid:20308738

7. Owens J, Adolescent Sleep Working Group, Committee on Adolescence. Insufficient sleep in adolescents and young adults: An update on causes and consequences. Pediatrics. 2014;134(3):e921-32.

8. Drake C, Roehrs T, Shambroom J, Roth T. Caffeine effects on sleep taken 0, 3, or 6 hours before going to bed. J Clin Sleep Med. 2013;9(11):1195-200. https://doi.org/10.5664/jcsm.3170 PMid:24235903

9. Yland J, Guan S, Emanuele E, Hale L. Interactive vs passive screen time and nighttime sleep duration among schoolaged children. Sleep Health. 2015;1(3):191-6. https://doi. org/10.1016/j.sleh.2015.06.007

PMid:27540566

10. Ikatan Dokter Anak Indonesia. Rekomendasi IDAI Selama Anak Menjalani Sekolah Dari Rumah; 2020. Available from: https:// www.idai.or.id. [Last accessed on 2020 Aug 02].

11. Kenney EL, Gortmaker SL. United States adolescents television, computer, videogame, smartphone, and tablet use: Associations with sugary drinks, sleep, physical activity, and obesity. J Pediatr. 2017;182:144-9. https://doi.org/10.1016/j. jpeds.2016.11.015

PMid:27988020

12. Cajochen C, Frey S, Anders D, Späti J, Bues M, Pross A, et al. Evening exposure to a light-emitting diodes (LED)-backlit computer screen affects circadian physiology and cognitive performance. J Appl Physiol (1985). 2011;110(5):1432-8. https:// doi.org/10.1152/japplphysiol.00165.2011

PMid:21415172

13. Asiyah SN, Putri AY. Relationship between Smartphone Addictions with Sleep Quality in Adolescents. Proceedings of the International Conference on Sustainable Health Promotion, 2018 October 9-11. Surabaya, Indonesia: Faculty of Psychology and Health, Sunan Ampel State Islamic University; 2018. p. 92-9.

14. Wiederhold BK. Children's screen time during the COVID-19 pandemic: Boundaries and etiquette. Cyberpsychol Behav Soc Netw. 2020;23(6):359-60. https://doi.org/10.1089/ cyber.2020.29185.bkw PMid:32437623

15. Eyimaya AO, Irmak AY. Relationship between parenting practices and children's screen time during the COVID-19 pandemic in Turkey. J Pediatr Nurs. 2021;56:24-9. https://doi. org/10.1016/j.pedn.2020.10.002

PMid:33181369

16. Buysse DJ, Hall ML, Strollo PJ, Kamarck TW, Owens J, Lee $\mathrm{L}$, et al. Relationships between the pittsburgh sleep quality index (PSQI), epworth sleepiness scale (ESS), and clinical/polysomnographic measures in a community sample. J Clin Sleep Med. 2008;4(6):563-71. https://doi.org/10.5664/ jcsm.27351 PMid:19110886

17. Setyowati A, Chung M. Validity and reliability of the Indonesian version of the pittsburgh sleep quality index in adolescents. Int $J$ Nurs Pract. 2020;e12856. https://doi.org/10.1111/ijn.12856 PMid:32632973

18. Ohida T, Osaki Y, Doi Y, Tanihata T, Minowa M, Suzuki K, et al An epidemiologic study of self-reported sleep problems among Japanese adolescents. Sleep. 2004;27(5):978-85. https://doi. org/10.1093/sleep/27.5.978 PMid: 15453558

19. LeBourgeois MK, Hale L, Chang AM, Akacem LD, MontgomeryDowns HE, Buxton OM. Digital media and sleep in childhood and adolescence. Pediatrics. 2017;140 Suppl 2:S92-6. https:// doi.org/10.1542/peds.2016-1758j PMid:29093040

20. Shochat T, Flint-Bretler O, Tzischinsky O. Sleep patterns, electronic media exposure and daytime sleep-related behaviours among Israeli adolescents. Acta Paediatr. 2010;99(9):1396-400. https://doi.org/10.1111/j.1651-2227.2010.01821.x PMid:20377536

21. Khalsa SB, Jewett ME, Cajochen C, Czeisler CA. A phase response curve to single bright light pulses in human subjects. J Physiol. 2003;549(3):945-52. https://doi.org/10.1113/ jphysiol.2003.040477

PMid: 12717008

22. Cajochen C, Chellappa SL, Schmidt C. Circadian and light effects on human sleepiness-alertness. In: Garbarino S, Nobili L, Costa G, editor. Sleepiness and Human Impact Assessment. Milan: Springer; 2014. p. 9-22. https://doi. org/10.1007/978-88-470-5388-5_2

23. Brainard GC, Hanifin JP, Greeson JM, Byrne B, Glickman G, Gerner $\mathrm{E}$, et al. Action spectrum for melatonin regulation in humans: Evidence for a novel circadian photoreceptor. J Neurosci. 2001;21(16):6405-12. https://doi.org/10.1523/ jneurosci.21-16-06405.2001

PMid:11487664

24. Chang AM, Aeschbach D, Duffy JF, Czeisler CA. Evening use of light-emitting eReaders negatively affects sleep, circadian timing, and next-morning alertness. Proc Natl Acad Sci USA 2015;112(4):1232-7. https://doi.org/10.1073/pnas.1418490112 PMid:25535358 